\title{
Development of acute lung injury after the combination of intravenous bleomycin and exposure to hyperoxia in rats
}

\author{
J G HAY, P L HASLAM, A DEWAR, B ADDIS, M TURNER-WARWICK, \\ G J LAURENT \\ From the Departments of Thoracic Medicine and Lung Pathology, Cardiothoracic Institute, London
}

ABSTRACT Pulmonary toxicity is an important adverse effect of bleomycin treatment. Very little is known of the mechanisms underlying the development of lung injury, especially after intravenous administration, or how it can be modulated. In this study acute lung injury induced by bleomycin has been examined in rats by assessment of alveolar lavage cell profiles, histological examination, and measurement of the total pulmonary extravascular albumin space. Intratracheal instillation of bleomycin $1.5 \mathrm{mg}$ resulted in a severe pneumonitis with influx of inflammatory cells into the alveoli as assessed by alveolar lavage, oedema of the alveolar walls, and up to an eight fold increase in the $\stackrel{\infty}{.}$ total pulmonary extravascular albumin space, maximal at 72 hours. Intravenous bleomycin $0 \cdot 15-5 \mathrm{mg}$ produced no detectable injury when assessed in these ways. Exposure to hyperoxia $(40-90 \%)$ after intravenous bleomycin, however, induced lung injury similar to that produced by intratracheal bleomycin. A much more severe injury followed administration of intravenous bleo- $\mathscr{\nu}^{\circ}$ mycin after an exposure to hyperoxia, which itself resulted in lung injury; but lung injury was still $\stackrel{\varnothing}{\varnothing}$ detectable after bleomycin when the exposure to hyperoxia was insufficient to induce changes in $\overrightarrow{\overrightarrow{0}}$ control animals. Lung injury was not observed when the exposure to hyperoxia preceded bleomycin 3 treatment. These results indicate the importance of oxygen in the pathways leading to acute lung injury following intravenous bleomycin. We conclude that exposure to oxygen might induce lung injury during and after bleomycin treatment, and suggest that in these circumstances oxygen therapy should be kept to a minimum.

Bleomycin is an antibiotic derived from Streptomyces verticillus with highly effective antitumour effects. ${ }^{1}$ It has become a major component of many chemotherapeutic regimens-in particular, for the treatment of testicular teratoma. ${ }^{2}$ It produces no toxic effects on the bone marrow but may cause major adverse effects on the lung. A 1-2\% mortality rate and an additional $2-3 \%$ incidence of pulmonary fibrosis were reported in early studies. ${ }^{3}$ In recent studies a $5-20 \%$ incidence of pneumonitis has been reported. ${ }^{4-7}$ This often takes the form of a respiratory distress syndrome, ${ }^{89}$ which is usually unpredictable, sometimes related to surgery, ${ }^{9-12}$ and sometimes fatal. ${ }^{6}$ Most affected patients, however, develop only minor changes in lung function. ${ }^{1314}$

Address for reprint requests: Dr J G Hay, Fazakerley Hospital, Liverpool L97AL.

Accepted 29 September 1986
The toxic effects of bleomycin on the lung have been used widely in experimental animals as a model $\delta$ of pulmonary fibrosis. The drug is usually administered by intratracheal instillation, which produces a 을 severe injury that leads to fibrosis. ${ }^{15-17}$ The mor- $D$ phological changes, ${ }^{18-20}$ the role of different cell types, ${ }^{21-26}$ and some of the biochemical mechanisms concerned in the accumulation of collagen have been $ᄋ$ described. ${ }^{2728}$ The effects of possible therapeutic $\tilde{O}$ agents have also been studied. ${ }^{29-32}$ Despite this work, little is known of the mechanisms by which 0 bleomycin induces the initial acute injury, particularly after intravenous administration, or how this can be $\underset{\mathbb{D}}{\overparen{D}}$ modulated-matters of obvious clinical importance. $\stackrel{?}{?}$

We have investigated the development of acute $\square$ lung injury in rats by assessment of the total pulmonary extravascular albumin space as a measure of $\stackrel{\Phi}{\Omega}$ protein exudation, light and electron microscopy $\stackrel{\mathbb{Q}}{\mathscr{Q}}$ appearances, and lavage cell profiles. The injury seen $\frac{a}{\sigma}$ after intratracheal instillation of bleomycin is con- 
trasted with the minimal changes that follow intravenous administration of bleomycin, which more closely mimics clinical practice. The mild reaction produced by intravenous bleomycin allows the evaluation of other factors important in the development of acute lung injury. We have previously ${ }^{33}$ described the importance of the availability of iron within the lungs on the development of injury, and here we describe the part played by oxygen.

\section{Methods}

\section{ANIMALS}

Male Lewis rats of $175-225 \mathrm{~g}$ weight were bred and maintained at the animal house of the Cardiothoracic Institute. All animals were allowed food and water ad libitum. Animals were anaesthetised with intramuscular fentanyl citrate $0.315 \mathrm{mg} / \mathrm{ml}$ and fluanisone $10 \mathrm{mg} / \mathrm{ml}$ (Hypnorm) at a dose of $0.05 \mathrm{ml} / 100 \mathrm{~g}$ body weight before every procedure, including intravenous injections.

\section{ASSESSMENT OF TOTAL PULMONARY}

\section{EXTRAVASCULAR ALBUMIN SPACE}

We estimated the total pulmonary extravascular albumin space by a method derived from the work of Wangensteen et al. ${ }^{34}$ Twenty four hours before being killed each animal received $1-2 \mu \mathrm{Ci}$ of human serum albumin labelled with iodine-125 $\left({ }^{125} \mathrm{I}\right)$ (Amersham International) intravenously in a total volume of $0.5 \mathrm{ml}$ of normal saline. Immediately before being killed each animal received an intravenous injection of 500 units $(0.5 \mathrm{ml})$ of mucous heparin. The animals were then exsanguinated by transection of the aorta. The pulmonary vasculature was flushed free of blood by ligating a cannula in the right ventricle and perfusing $12 \mathrm{ml}$ of phosphate buffered saline. The lungs were then removed from the animal, dissected free of main bronchi and blood vessels, and placed in a counting vial. Duplicates of plasma were also counted in a gamma counter. Total pulmonary extravascular albumin space was calculated as the ratio of the total radioactivity in the lungs to that in $1 \mathrm{ml}$ of plasma.

\section{EXPOSURE TO OXYGEN}

Animals were placed in a plastic chamber, which was continually flushed with a mixture of air and oxygen to maintain the desired concentration of oxygen. Carbon dioxide was removed by a tray of soda lime placed in the chamber. Periodic checks of the oxygen concentration were made and it was possible to keep this within $5 \%$ of the desired concentration.

\section{EXPERIMENTAL GROUPS}

\section{Intratracheal bleomycin}

Four groups of animals received $1.5 \mathrm{mg}$ of bleomycin (supplied by Lundbeck) in $0.3 \mathrm{ml}$ of normal saline by peroral tracheal instillation. A control group of animals received $0.3 \mathrm{ml}$ of normal saline. Animals were killed 24, 48, 72 and 96 hours after instillation of bleomycin.

\section{Intravenous bleomycin alone and in combination with $90 \%$ oxygen for 48 hours}

Five groups of animals were studied.The first received $0.5 \mathrm{ml}$ of normal saline by intravenous injection, and the others $0 \cdot 15,1 \cdot 5,5$, and $15 \mathrm{mg}$ of bleomycin in the same volume of normal saline. Half of the animals in each group were left in air and the other half placed in an atmosphere of $90 \%$ oxygen for 48 hours immediately after the intravenous injection. All the animals were killed 72 hours after the intravenous injection of bleomycin.

\section{Effects of preoxygenation}

A group of animals was placed in $90 \%$ oxygen for 48 hours and then given an intravenous injecton of either saline or bleomycin $5 \mathrm{mg}$. All animals were killed 72 hours after the intravenous injection.

\section{Effects of delayed exposure to oxygen}

Three groups of animals were studied. All received $5 \mathrm{mg}$ of bleomycin by intravenous injection. In each group half were exposed to 48 hours of $90 \%$ oxygen and half remained in room air. The exposure to oxygen was delayed for one, three, and seven days after intravenous bleomycin. Animals were killed 72 hours after their exposure to oxygen.

\section{Effects of duration of oxygen exposure}

Two groups of animals were studied. In each group half received an intravenous injection of bleomycin $5 \mathrm{mg}$ and half saline. The first group were exposed to four and the second to 24 hours of $90 \%$ oxygen immediately after the intravenous injection. All animals were killed 72 hours after injection.

\section{Effects of exposure to $75 \%$ and $40 \%$ oxygen for 48 hours}

Two groups of animals were studied. Half of the animals in each group received an intravenous injection of bleomycin $5 \mathrm{mg}$, and the other half saline. The first group were exposed to $75 \%$ and the second $40 \%$ oxygen for 48 hours immediately after the injection. Total pulmonary extravascular albumin space was assessed at 72 hours as before.

\section{HISTOLOGY AND LAVAGE}

The profile of cell types recovered by lavage and histological appearances of the lung were assessed in the following five groups: (1) intratracheal bleomycin at 72 hours; (2) intravenous bleomycin $5 \mathrm{mg}$; (3) intra- 
venous bleomycin $5 \mathrm{mg}$ plus 48 hours' $90 \%$ oxygen; (4) intravenous saline plus 48 hours' $90 \%$ oxygen; (5) control animals having no treatment.

After exsanguination, the right lungs were lavaged with $20 \mathrm{ml}$ phosphate buffered saline in $4 \mathrm{ml}$ aliquots administered via a cannula in the right main bronchus. Both lungs were then inflated with Carson's fixative ${ }^{35}$ until the pleural surface was free from folds. The lungs were then placed into the same fixative for 48 hours. The left lungs were embedded in paraffin wax after a small portion had been removed for electron microscopy. Sections were stained with haematoxylin and eosin. Cytocentrifuge preparations were made of lavage cells and stained with MayGrünwald Giemsa and non-specific esterase. ${ }^{36} 37$

\section{BLEOMYCIN CLEARANCE}

So that we could determine the rate of clearance of bleomycin from plasma, lung tissue, and muscle, 21 animals received $5 \mathrm{mg}$ of bleomycin intravenously, to which $200 \mu \mathrm{Ci}$ of bleomycin labelled with indium-111 ( $\left.{ }^{111} \mathrm{In}\right)$ (Amersham International) had been added. Animals were killed in groups of three at the following time points: one, three, and six hours; one, three, five, and seven days. Lungs were flushed free of blood as described above and total radioactivity was measured in a gamma counter; a portion of thigh muscle and duplicate plasma samples were also counted. Results are expressed as the percentage of the radioactivity in $1 \mathrm{~g}$ of tissue or $1 \mathrm{ml}$ of plasma to the total radioactivity injected. To correct for decay of the isotope we prepared at the start of the study a vial containing an amount of ${ }^{111}$ In bleomycin identical to that injected into the animals. This vial was gamma counted at each time point to provide a value for the total radioactivity injected.

ANALYSIS OF DATA

The results were assessed for significance with the Mann-Whitney $U$ test for non-parametric data. The same conditions were repeated on several occasions for certain groups in different experiments. The measurement of total pulmonary extravascular albumin space was found to be highly reproducible, and no

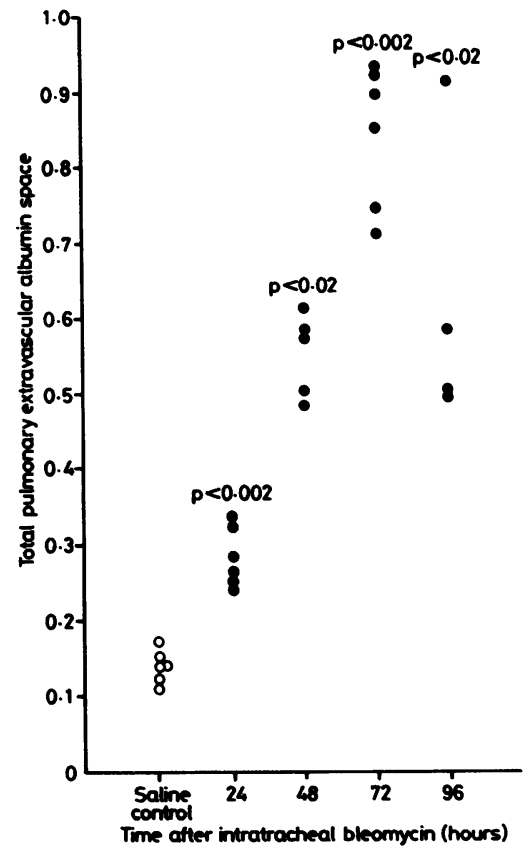

Fig 1 Time course of the development of lung injury after the intratracheal instillation of bleomycin $(1.5 \mathrm{mg})$ as assessed by the total pulmonary extravascular albumin space. $p$ values refer to the difference between bleomycin treated animals and saline treated controls.

significant difference was found between groups when the same conditions were repeated. These data have therefore been cumulated to increase the number of animals in groups that appear in more than one experiment when the same conditions were repeated.

\section{Results}

Intratracheal bleomycin produced up to an eightfold increase in total pulmonary extravascular albumin space, which was maximal at 72 hours (fig 1). This corresponded to the histological findings of perivascular and alveolar wall oedema, inflammatory cell

Cell types as percentages of the total cells present in the lavage fluid (with standard deviations in parentheses)

\begin{tabular}{|c|c|c|c|c|c|}
\hline \multirow[b]{2}{*}{ Cell } & \multicolumn{4}{|c|}{ Intravenous } & \multirow[b]{2}{*}{ Tracheal Blm } \\
\hline & Saline & $B l m$ & Saline $+\mathrm{O}_{2}$ & $B l m+O_{2}$ & \\
\hline $\begin{array}{l}\text { Neutrophil } \\
\text { Eosinophil } \\
\text { Macrophage } \\
\text { Lymphocyte } \\
\text { Monocyte }\end{array}$ & $\begin{array}{c}0.2(0.3) \\
0.1(0.2) \\
98(1) \\
1(0.7) \\
1(1)\end{array}$ & $\begin{array}{l}0.9(1) \\
0 \\
97(3) \\
1(2) \\
1(0 \cdot 6)\end{array}$ & $\begin{array}{c}11(6)^{*} \\
0.7(0 \cdot 5) \\
86(7) \\
1(0 \cdot 8) \\
2(1)\end{array}$ & $\begin{array}{l}30(9)^{*} \dagger \\
1 \cdot 3(1)^{*} \dagger \\
55(11) \\
5(1 \cdot 3)^{*}+ \\
9(3)^{*}+\end{array}$ & $\begin{array}{c}49(9)^{*} \\
1(1)^{*} \\
4(1) \\
33(7)^{*} \\
14(3)^{*}\end{array}$ \\
\hline
\end{tabular}

$* \mathrm{p}<0.002$ for comparison with intravenous saline.

$t \mathrm{p}<0.002$ for comparison with intravenous saline and oxygen.

Bim-bleomycin; $\mathrm{O}_{2}$-oxygen. 
infiltration, and alveolar exudate. Lavage cell profiles at this time (table) showed a significant influx of neutrophils, lymphocytes, and monocytes. In contrast intravenous bleomycin produced a significant change in total pulmonary extravascular albumin space only at the $15 \mathrm{mg}$ dose (fig 2 ). No evidence of injury was apparent, as assessed by lavage profiles or light and electron microscopic appearances, in the $5 \mathrm{mg}$ group by comparison with the saline control group.

When intravenous bleomycin was given simultaneously with 48 hours of $90 \%$ oxygen a significantly greater total pulmonary extravascular albumin space was seen in the groups receiving all the doses of bleo-

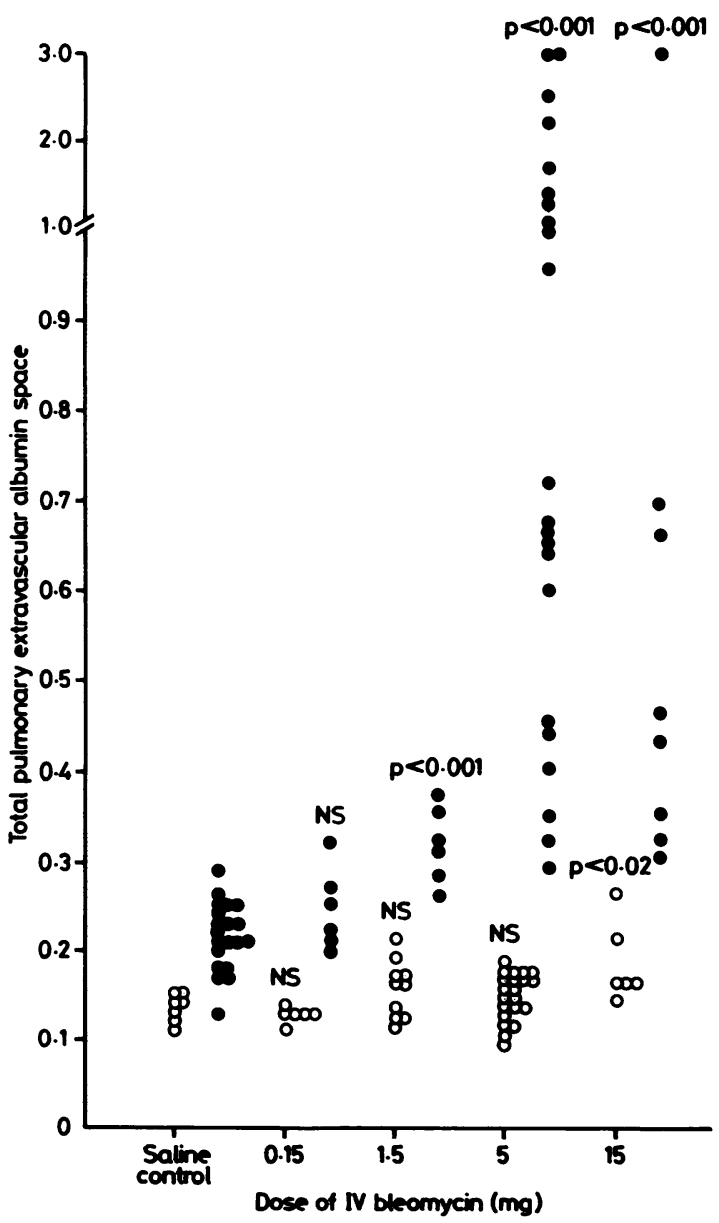

Fig 2 Effects of intravenous bleomycin on the total pulmonary extravascular albumin space at 72 hours. Open circles refer to animals left in room air and closed circles to animals placed in $90 \%$ oxygen for 48 hours immediately after the injection. For bleomycin treated animals $p$ values refer to the saline group in oxygen for the closed circles and to the saline group in air for the open circles. IV-intravenous. mycin used except $0.15 \mathrm{mg}$ than in the saline and oxygen control group (fig 2). For animals receiving $5 \mathrm{mg}$ of bleomycin and oxygen, changes in lavage profiles (table) and histological appearances were similar to those observed after intratracheal bleomycin, although the lymphocytic infiltrate was less noticeable. The group receiving intravenous saline and exposed to $\mathbf{9 0 \%}$ oxygen showed a significantly greater total pulmonary extravascular albumin space than the saline in air group (fig 2; p $<0.002$ ), with a small influx of neutrophils into the lavage fluid but normal light and electron microscopic appearances. Shorter exposures to $90 \%$ oxygen (fig 3 ), or lower concentrations of oxygen for 48 hours (fig 4), which produced no changes in control animals, induced a significant increase in total pulmonary extravascular albumin space in combination with $5 \mathrm{mg}$ of bleomycin. The magnitude of the injury as assessed by total pulmonary extravascular albumin space was, however, considerably less than that following $90 \%$ oxygen for $\mathbf{4 8}$ hours.

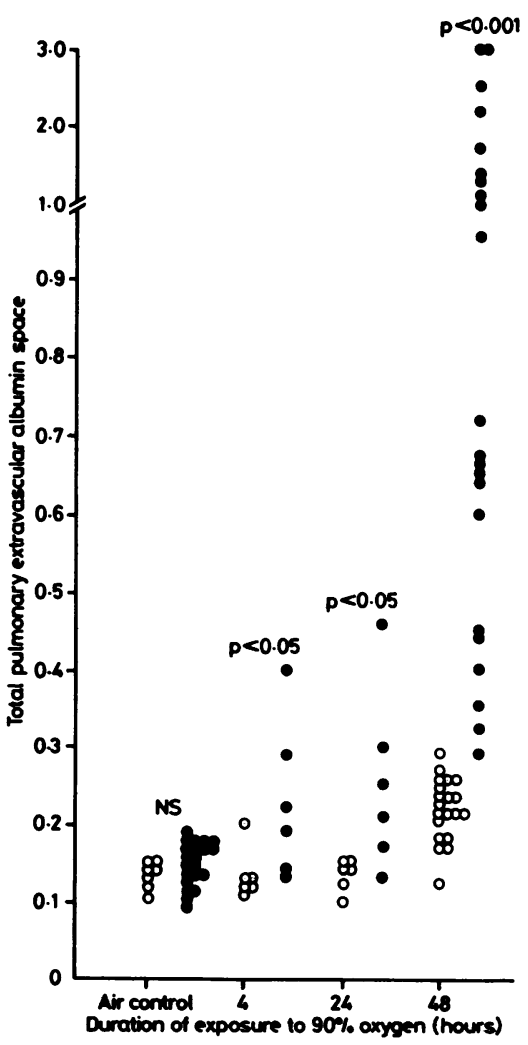

Fig 3 Effects of duration of exposure to $90 \%$ oxygen immediately after the intravenous injection of bleomycin $5 \mathrm{mg}$ (closed circles) or saline (open circles). Animals were killed 72 hours after the injection of bleomycin or saline. 
Potentiation of lung injury was not seen when exposure to oxygen preceded the intravenous injection of bleomycin; the median value for total pulmonary extravascular albumin space obtained for animals receiving $5 \mathrm{mg}$ of intravenous bleomycin after exposure to $90 \%$ oxygen for 48 hours was 0.17 (range $0 \cdot 12-0 \cdot 19$ ), almost identical to the values seen in controls receiving saline $0 \cdot 15$ (range $0 \cdot 13-0 \cdot 17$ ). If exposure was delayed for one or three days a significant injury was still seen, but not if the delay was extended to seven days after intravenous bleomycin (fig 5).

Seven animals died before their total pulmonary extravascular albumin space could be assessed. They were in five different experimental groups, and at different stages of the experiments, although death usually occurred soon after induction of anaesthesia.

The results of ${ }^{111}$ In bleomycin clearance from plasma, lung, and muscle are shown in figure 6. After

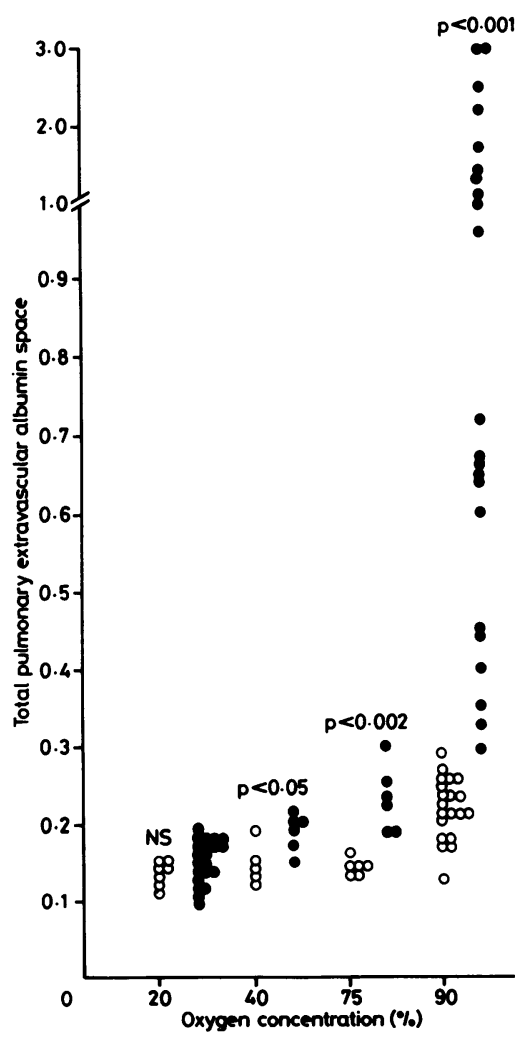

Fig 4 Effects of exposure to different concentrations of oxygen for 48 hours after intravenous saline (open circles) or bleomycin $5 \mathrm{mg}$ (closed circles). Animals were killed at 72 hours as before. $p$ values refer to comparison of the saline and bleomycin groups exposed to the same concentration of oxygen. the intravenous injection of the radiolabelled bleomycin, uptake into both tissues was rapid, maximal concentrations being reached within one hour. At this time the concentration of bleomycin in the lung was about twice that in skeletal muscle, a difference that was maintained later as the isotope was lost from both tissues. The loss of radioactivity did not follow a simple first order exponential; there was a rapid loss in the first 24 hours followed by a first order decay thereafter in both tissues with a half life of about 3.5 days.

\section{Discussion}

The pulmonary reaction that follows administration of intratracheal bleomycin to animals has been extensively used as a model of pulmonary fibrosis. ${ }^{15-1728}$ A severe lung injury is invariable, and the mechanisms underlying the subsequent fibrosis that develops

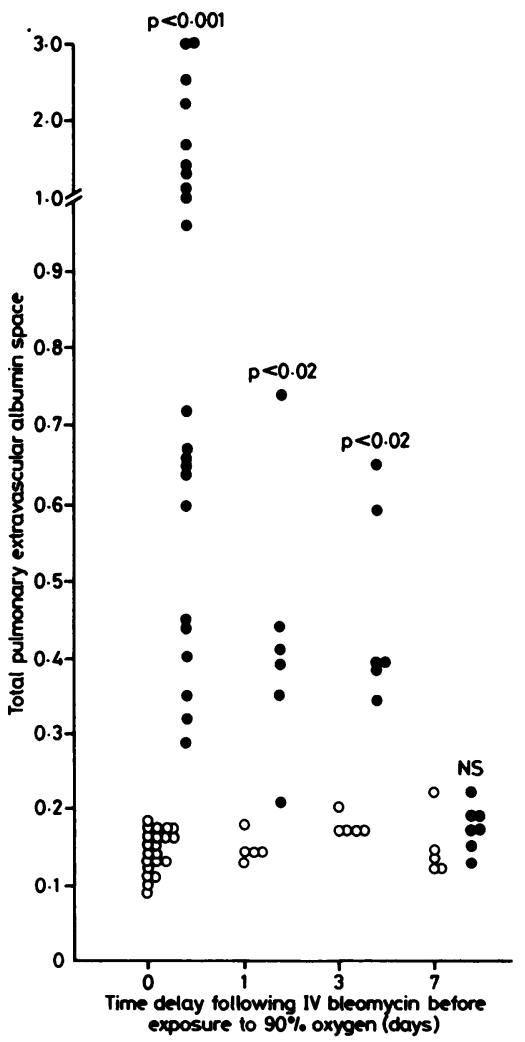

Fig 5 Effects of delaying exposure to 48 hours of $90 \%$ oxygen for the times shown (days). Animals were killed 72 hours after being placed in the oxygen. The open circles refer to control animals that received bleomycin $5 \mathrm{mg}$ but remained in room air for the duration of the experiment. IV-intravenous. 


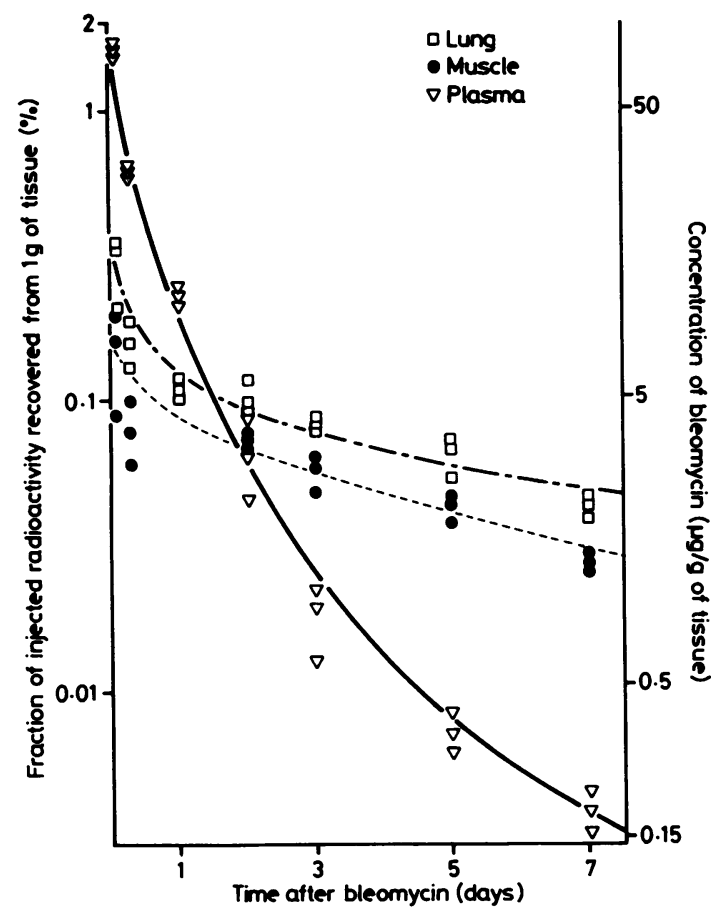

Fig 6 Clearance of indium-111 labelled bleomycin after an intravenous injection of tracer amounts of the labelled compound with bleomcyin $5 \mathrm{mg}$.

over several weeks have been the subject of much research. Relatively little is known of the mechanisms by which bleomycin induces the initial acute lung damage, which is of great importance clinically as the development of the respiratory distress syndrome is a serious adverse effect of bleomycin..$^{9-12}$ In this paper we have assessed acute lung injury by measuring the total extravascular albumin space in the lungs. We have shown how this measurement is related to the injury developing over the first 96 hours, following the more usual intratracheal model of bleomycin injury. A maximum increase was seen after 72 hours, and this corresponded to the histological findings of a pneumonitis with alveolar wall oedema and invasion of inflammatory cells. Increased percentages of neutrophils and lymphocytes were seen in the alveolar lavage fluid. By contrast, when much larger doses than were given by intratracheal instillation were administered intravenously, only a very small change in total pulmonary extravascular albumin space was seen in the group receiving a 10 times greater dose, and no changes occurred in lavage cell profiles, histological appearances, or total pulmonary extravascular albumin space in the group receiving a threefold increase in dose. These data show how the mea- surement of total pulmonary extravascular albumin space corresponds with the early histological findings and indicate its value as a simple technique for use in the assessment of acute lung injury. The difference in response for animals receiving intravenous bleomycin from those receiving the same dose by intratracheal instillation is almost certainly related to the concentrations obtained in lung tissue (although we have not compared concentrations). After intratracheal instillation most of the drug must be absorbed through the lungs, yet one hour after intravenous injection only $0.2 \%$ of the injected dose could be recovered from the lungs (fig 6 ).

By administering bleomycin intravenously at a dose which produced no evidence of lung injury on its own we have been able to investigate the potential role of oxygen in producing lung injury in combination with bleomycin. The clinical problem with patients receiving bleomycin is why only a small proportion develop an acute lung injury. Surgery is thought to be a precipitating factor, perhaps as a result of exposure to oxygen or fluid imbalance. ${ }^{10-12}$ There is still, however, continuing debate about the risk of exposing patients receiving bleomycin to oxygen. ${ }^{38-40}$

In animal models the development of lung injury after intratracheal bleomycin has been found to be potentiated by oxygen when assessed by mortality and histology, ${ }^{4142}$ and lung weights and physiological indices. ${ }^{43}$ The potentiation of an established injury is, however, of less relevance to the clinical problem than the initial induction of injury. Hyperoxia has been shown to potentiate established lung injury induced by several different agents. ${ }^{44}$ Some workers have used doses and routes of administration of bleomycin that alone produce no changes in the parameters of fibrosis they have been measuring. Hakkinen et $\mathrm{al}^{45}$ have shown an increased mortality after intraperitoneal bleomycin in mice placed in $80 \%$ oxygen for 120 hours, and increased collagen deposition at three weeks in animals placed in $70 \%$ oxygen for seven days immediately after the administration of bleomycin, the bleomycin alone producing no changes. Tryka et $a l^{46}$ have shown that exposing hamsters to $70 \%$ oxygen for 72 hours after very small doses of intratracheal bleomycin, which in air produce no morphological abnormalities, resulted in focal interstitial fibrosis at $\mathbf{3 0}$ days.

We have shown that the administration of bleomycin $(5 \mathrm{mg})$ intravenously, which is the usual route in clinical practice, produces no evidence of acute lung injury as assessed by light and electron microscopy, lavage cell profiles, or the assessment of total pulmonary extravascular albumin space. As little as four hours exposure to $90 \%$ oxygen, however, produces a significant increase in total pulmonary extravascular 
albumin space. After 48 hours of exposure to oxygen an acute pneumonitis is seen. These data show how an acute lung injury might be induced by intravenous bleomycin treatment in clinical practice.

The considerable spread in total pulmonary extravascular albumin space values in animals exposed to oxygen after intravenous bleomycin was of interest, and may represent individual variation in the sensitivity to bleomycin between different animals. It may also represent different rates of progression of lung injury. Acute lung injury follows a sequence of capillary leakage of protein, followed by interstitial proteinaceous oedema when the lymphatic system has been overwhelmed, and finally intra-alveolar exudate. This may either resolve, lead to the death of the animal, or become organised by fibrosis. We have not followed the natural history of this model, but it is interesting to speculate whether the degree of any subsequent fibrosis might be related to the extent of acute injury as assessed in terms of total pulmonary extravascular albumin spaces.

One possible explanation of the increased injury seen when bleomycin is given to animals in an atmosphere enriched in oxygen is that it is simply the superimposition of two pulmonary insults. The lack of potentiation seen by preoxygenation argues against this, as does the potentiation seen by only four hours of oxygen and lower percentages of oxygen, which alone do not produce any lung injury. It seems more reasonable to conclude that oxygen increases the pulmonary toxicity of bleomycin. This would be in keeping with the current views on the mechanism of action of bleomycin based on in vitro data ${ }^{47}$ The formation of an active complex with iron and oxygen is an essential step in the cleavage of the polynucleotide chain of DNA by bleomycin. This can be summarised as:

$$
\begin{aligned}
& \text { DNA }+\mathrm{O}_{2}+\mathrm{Fe}(\mathrm{II})+\mathrm{BLM} \rightarrow \\
& \text { DNA . } \mathrm{Fe}(\mathrm{II}) . \mathrm{BLM} . \mathrm{O}_{2} \rightarrow \\
& \text { DNA . Activated bleomycin } \stackrel{\mathrm{H}_{2} \mathrm{O}_{2}}{\leftrightarrows} \\
& \text { BLM . Fe(III) + cleavage products of DNA. }
\end{aligned}
$$

The fact that oxygen tensions are higher in lung than in other tissue may explain why the lung is more vulnerable to bleomycin induced injury and particularly so when combined with hyperoxia. We have also recently shown in vivo ${ }^{33}$ that increasing the availability of iron within the lungs increases bleomycin induced injury, giving further evidence that this scheme of bleomycin activation operates in vivo.

The ability of oxygen to potentiate bleomycin injury when given three days but not seven days after the bleomycin may be related to lung clearance of bleomycin. Figure 6 shows that over this period lung tissue levels fall by a factor of 2 and plasma levels fall by a factor of 5 . From this figure it can also be seen that lung concentrations of bleomycin are higher, but only slightly so, than muscle. Although this is a possible explanation for the increased sensitivity of lung to bleomcyin injury, this may also be explained by the fact that oxygen tensions are higher in the lung than in other tissues.

There are always dangers in attempting to extrapolate data obtained from animal studies to formulate advice on the clinical management of patients, but often animal models are the only way to analyse possible harmful interactions and elucidate mechanisms. In this study we have examined only the consequences of a single injection of bleomycin, whereas in clinical practice repeated doses are given. The $0.15 \mathrm{mg}$ group $(0.5 \mathrm{mg} / \mathrm{kg})$ corresponds to the dose given to humans in a single injection. ${ }^{248}$ This did not lead to lung injury in combination with hyperoxia. An accumulation of bleomycin within the lungs with repeated doses may be an important factor, and Adamson et al have shown that lung concentrations in mice do increase with repeated doses. ${ }^{49}$

We have also found that very high concentrations of oxygen for 24-48 hours were required to produce severe acute injury, but smaller yet highly significant increases in pulmonary extravascular albumin space were still seen at lower concentrations, which are commonly used in clinical practice and anaesthesia. Prolonged exposure to high concentrations occurs in patients who are ventilated in intensive care units; and during, for example, rigid bronchoscopy and reversal of anaesthesia short exposures to $100 \%$ oxygen occur. ${ }^{12}$ In addition, there may be species variation in the sensitivity to oxygen ${ }^{50}$ and bleomycin toxicity.

In conclusion, we have shown that large doses of bleomycin (up to $20 \mathrm{mg} / \mathrm{kg}$ ) given intravenously produced no evidence of acute lung injury. With the addition, however, of short exposures to hyperoxia they were able to produce acute injury. The mechanism of this interaction is almost certainly an increased chemical activation of bleomycin in the presence of hyperoxia, and not the simple superimposition of two lung insults. This is in accord with in vitro data on the activation of bleomycin, and our previous findings ${ }^{33}$ on the importance of the availability of iron in the lungs on bleomycin pulmonary toxicity. This has implications for the management of patients receiving bleomycin when surgery is planned, and for patients with respiratory distress receiving bleomycin. Despite the limitations of extrapolating from animal experiments it seems appropriate to keep exposure to oxygen to a minimum in these groups of patients.

We are grateful to Mr T Betts, curator of the animal house, for the supply of animals and the oxygen isolator. We would also like to acknowledge the secre- 
tarial assistance given by Miss Alex Close. This work was supported by a grant from the Medical Research Council, and we are grateful to Mrs A Powell for financial help provided in memory of $\mathrm{Mr} \mathrm{K}$ Powell.

\section{References}

1 Umezawa H, Maeda K, Takeucht T, Akami Y. New antibiotics, bleomcyin A and B. J Antibiot (Tokyo) 1966;19:200-9.

2 Garnick MB. Advanced testicular cancer: treatment choices in the "land of plenty". J Clin Oncol 1985;3:294-7.

3 Blum RH, Carter SK, Agre K. A clinical review of bleomycin. Cancer 1973;31:903-14.

4 Van Barneveld PWC, Van Der Mark THW, Sleijfer DTH, et al. Predictive factors for bleomycin-induced pneumonitis. Am Rev Respir Dis 1984;130:1078-81.

5 Dalgleish AG, Woods RL, Levi JA. Bleomycin pulmonary toxicity: its relationship to renal dysfunction. Med Pediatr Oncol 1984;12:313-7.

6 White DA, Stover DE. Severe bleomycin-induced pneumonitis: clinical features and response to corticosteroids. Chest 1984;86:723-8.

7 Bauer KA, Skarin AT, Balikian JP, Garnick MB, Rosenthal DS, Canellos GP. Pulmonary complications associated with combination chemotherapy programs containing bleomcyin. Am J Med 1983;74:557-63.

8 Bedrossian CWM, Luna MA, Mackay B, Lichtiger B. Ultrastructure of pulmonary bleomycin toxicity. Cancer 1973;32:44-51.

9 Jones AW. Bleomycin lung damage: the pathology and nature of the lesion. Br J Dis Chest 1978;72:321-6.

10 Donohue JP, Rowland RG. Complications of retroperitoneal lymph node dissection. J Urol 1981;125: 338-40.

11 Goldiner PL, Carlon GC, Cvitkovic E, Schweizer O, Howland WS. Factors influencing postoperative morbidity and mortality in patients treated with bleomycin. Br Med J 1978;i:1664-7.

12 Douglas MJ, Coppin CML. Bleomycin and subsequent anaesthesia: a retrospective study at Vancouver General Hospital. Can Anaesth Soc J 1980;5:449-52.

13 Luursema BP, Star-Kroesen MA, Van Der Mark TH, Sleyfer DT, Koops HS, Peset R. Bleomycin-induced changes in the carbon monoxide transfer factor of the lungs and its components. Am Rev Respir Dis 1983;128:880-3.

14 Comis RL, Kuppinger MS, Ginsberg SJ, et al. Role of single-breath carbon monoxide-diffusing capacity in monitoring the pulmonary effects of bleomycin in germ cell tumor patients. Cancer Res 1979;39:5076-80.

15 Snider GL, Celli BR, Goldstein RH, O'Brien JJ, Lucey EC. Chronic interstitial pulmonary fibrosis produced in hamsters by endotracheal bleomycin. Am Rev Respir Dis 1978;117:289-97.

16 Phan SH, Thrall RS, Ward PA. Bleomycin-induced pulmonary fibrosis in rats: biochemical demonstration of increased rate of collagen synthesis. Am Rev Respir Dis
1980;121:501-6.

17 Laurent GJ, McAnulty RJ, Corrin B, Cockerill P. Biochemical and histological changes in pulmonary fibrosis induced in rabbits with intratracheal bleomycin. Eur J Clin Invest 1981;11:441-8.

18 Chandler DB, Hyde DM, Giri SN. Morphometric estimates of infiltrative cellular changes during the development of bleomycin-induced pulmonary fibrosis in hamsters. Am J Pathol 1983;112:170-7.

19 Thrall RS, Barton RW, D'Amato DA, Sulavik SB. Differential cellular analysis of bronchoalveolar lavage fluid obtained at various stages during the development of bleomycin-induced pulmonary fibrosis in the rat. Am Rev Respir Dis 1982;126:488-92.

20 Thrall RS, Barton RW. A comparison of lymphocyte populations in lung tissue and in bronchoalveolar lavage fluid of rats at various times during the development of bleomycin-induced pulmonary fibrosis. $\mathrm{Am}$ Rev Respir Dis 1984;129:279-83.

21 Clark JG, Kostal KM, Marino BA. Bleomycin-induced pulmonary fibrosis in hamsters. $J$ Clin Invest 1983;72:2082-91.

22 Wesselius LJ, Catanzaro A, Wasserman SI. Neutrophil chemotactic activity generation by alveolar macrophages after bleomycin injury. Am Rev Respir Dis 1984;129:485-90.

23 Schrier DJ, Phan SH, McGarry BM. The effects of the nude (nu/nu) mutation on bleomycin-induced pulmonary fibrosis. Am Rev Respir Dis 1983;127:614-7.

24 Schrier DJ, Phan SH. Modulation of bleomycin induced pulmonary fibrosis in the BALB/c mouse by cyclophosphamide-sensitive $\mathrm{T}$ cells. Am $\mathrm{J}$ Pathol 1984;116:270-8.

25 Phan SH, Schrier D, McGarry B, Duque RE. Effect of the beige mutation on bleomycin-induced pulmonary fibrosis in mice. Am Rev Respir Dis 1983;127:456-9.

26 Thrall RS, Phan SH, McCormick JR, Ward PA. The development of bleomycin-induced pulmonary fibrosis in neutrophil-depleted and complement-depleted rats. Am J Pathol 1981;105:76-81.

27 Laurent GJ, McAnulty RJ. Protein metabolism during bleomycin-induced pulmonary fibrosis in rabbits. In vivo evidence for collagen accumulation because of increased synthesis and decreased degradation of the newly synthesized collagen. Am Rev Respir Dis 1983;128:82-8.

28 Laurent GJ. Biochemical pathways leading to collagen deposition in pulmonary fibrosis. Fibrosis. London: Ciba Foundation, 1985:222-33. (Ciba Foundation Symposium.)

29 Phan SH, Thrall RS, Williams C. Bleomycin-induced pulmonary fibrosis effects of steroid on lung metabolism. Am Rev Respir Dis 1981;124:428-34.

30 Thrall RS, McCormick JR, Jack RM, McReynolds RA, Ward PA. Bleomycin-induced pulmonary fibrosis in the rat. Am J Pathol 1979;95:117-30.

31 Chandler DB, Fulmer JD. The effect of deferoxamine on bleomycin-induced lung fibrosis in the hamster. $\mathrm{Am}$ Rev Respir Dis 1985;131:596-8.

32 Phan SH, Fantone JC. Inhibition of bleomycin-induced pulmonary fibrosis by lipopolysaccharide. Lab Invest 1984;50:587-91. 
33 Hay JG, Haslam PL, Turner-Warwick M, Laurent GJ. The importance of iron in the development of acute lung injury following intravenous bleomycin. Free Rad Res Comm (in press).

34 Wangensteen D, Yankovich R, Hoidal J, Niewoehner D. Bleomycin-induced changes in pulmonary microvascular albumin permeability and extravascular albumin space. Am Rev Respir Dis 1983;127:204-8.

35 Carson JH, Martin JH, Lynn JA. Formaldehyde fixation for electron microscopy - a re-evaluation. Am J Clin Pathol 1973;59:365-73.

36 Haslam PL, Allan F, Watling AF, Barrett C, Morris L, Turner-Warwick $M$. Impaired antibody-dependent cell-mediated cytotoxicity in cryptogenic fibrosing alveolitis (synonym: idiopathic pulmonary fibrosis). Clin Exp Immunol 1982;49:59-66.

37 Haslam PL, Turton CWG, Lukoszek A, et al. Bronchoalveolar lavage fluid cell counts in cryptogenic fibrosing alveolitis and their relation to therapy. Thorax 1980;35:328-39.

38 Mandelbaum I, Williams SD, Einhorn LH. Aggressive surgical management of testicular carcinoma metastatic to lungs and mediastinum. Ann Thorac Surg 1980;30:224-9.

39 LaMantia KR, Glick JH, Marshall BE. Supplement oxygen does not cause respiratory failure in bleomycintreated surgical patients. Anesthesiology 1984;60:65-7.

40 Goldiner PL, Rooney SM. In defense of restricting oxygen in bleomycin-treated surgical patients. Anesthesiology 1984;61:226-7.

41 Tryka AF, Godleski JJ, Brain JD. Differences in effects of immediate and delayed hyperoxia exposure on bleomycin-induced pulmonary injury. Cancer Trea民̃. Rep 1984;68:759-64.

42 Berend N. The effect of bleomycin and oxygen on ras? lung. Pathology 1984;16:136-9.

43 Rinaldo J, Goldstein RH, Snider GL. Modification of̂ oxygen toxicity after lung injury by bleomycin in ham $\overline{-\bar{s}}$ sters. Am Rev Respir Dis 1982;126:1030-3.

44 Hakkinen PJ, Morse CC, Martin FM, Dalbey WE, Has chek WM, Witschi HR. Potentiating effects of oxygenes in lungs damaged by methylcyclopentadienyl man- $\overrightarrow{0}$ ganese tricarbonyl, cadmium chloride, oleic acid, andantitumor drugs. Toxicol Appl Pharmacol 1983;67 $\vec{\omega}$ 55-69.

45 Hakkinen PJ, Whiteley JW, Witschi HR. Hyperoxia, bu民 not thoracic $\mathrm{X}$ irradiation, potentiates bleomycin- and cyclophosphamide-induced lung damage in mice. $A m \mathrm{~N}$ Rev Respir Dis 1982;126:281-5.

46 Tryka AF, Skornik WA, Godleski JJ, Brain JD. Potentiation of bleomycin-induced lung injury by exposure to 70\% oxygen. Am Rev Respir Dis 1982;126:1074-9.

47 Burger RM, Peisach J, Horwitz SB. Activated bleomy- cin. A transient complex of drug, iron and oxygen that degrades DNA. J Biol Chem 1981;256:11636-44.

48 Alberts DS, Chen HSG, Liu R, et al. Bleomycin pharma- $\overrightarrow{0}$ cokinetics in man. Cancer Chemother Pharmacopo 1978;1:177-81.

49 Adamson IYR, Bowden DH. Bleomycin-induced injuryo and metaplasia of alveolar type 2 cells. Am J Pathok 1979;96:531-45.

50 Slade R, Stead AG, Graham JA, Hatch GE. Com parison of lung antioxidant levels in humans and labo-D ratory animals. Am Rev Respir Dis 1985;131:742-6. 